\title{
COMPARING INTRODUCTORY COURSE PLANNING AMONG FULL-TIME AND PART-TIME FACULTY
}

\author{
Malcolm A. Lowther, Joan S. Stark, \\ Michele L. Genthon, and Richard J. Bentley
}

Using data from a nationally representative survey of facuity teaching introductory college courses, this exploratory study compares course planning procedures of full-time and part-time faculty teaching courses in eight academic fields. The choice of variables examined was guided by a general model of course design developed from earlier studies of course planning. To control for discipline-related differences in faculty planning assumptions, separate analyses were conducted for the eight fields. No key differences were found between full-time and part-time faculty on the primary factors under investigation: substantive content-related influences on courses, strength of influence within the instructional environment, and planning steps and content arrangements faculty preferred.

As they plan college courses, instructors make decisions about what content should be taught, consider various factors affecting the teaching and learning process, and choose from alternative strategies for engaging students with the content. Course planning also includes selecting ways to obtain feedback about student learning in order to improve future decision-making processes. Since the course is the traditional medium for undergraduate study, course planning is a fundamental educational activity of college faculty. Thus, an understanding of how faculty plan their courses is an important step in improving teaching and learning.

Studies of how precollege teachers think when they plan began only recently (Clark and Peterson, 1986) even though $\mathrm{K}-12$ teachers have long received

Malcolm A. Lowther, Joan S. Stark, Michele L. Genthon, and Richard J. Bentley, National Center for Research to Improve Postsecondary Teaching and Learning, University of Michigan. Address correspondence to: Dr. Malcolm A. Lowther, 2400 School of Education, The University of Michigan, Ann Arbor, MI 48109-1259. 
extensive training in course planning. The recent studies, many of which are ethnographic, now comprise a body of literature sometimes referred to as "teacher thought" research. For college teachers, who typically lack specific preparation for the course planning role, studies are even more scarce (Stark and Lowther, 1986; Lowther and Stark, 1990). Until very recently, there has not been a higher education literature about the assumptions and decisions faculty members make as they plan courses.

During the past four years, a series of interview and survey studies of planning among college faculty has produced an organizing framework for continued study. This framework is based on evidence that a faculty member's background, disciplinary views, and related beliefs about the purpose of education combine to provide the single strongest influence on planning. Although less influential generally, situational influences (ranging from student preparedness to the academic calendar) serve as "filters" of varying potency through which the disciplinary notions are "screened" and modified. Thus, the framework was named "the contextual filters model" of course planning. The name suggests that faculty think differently about the "context" influences than about the "content," which is represented in the model by the combined influence of their background, discipline, and educational beliefs (Stark, Lowther, Ryan, and Genthon, 1988; Stark, Lowther, Ryan, Bomotti, Genthon, Haven, and Martens, 1988; Stark, Lowther, Bentley, Ryan, Genthon, Martens, and Wren, 1989).

The contextual filters model provides a heuristic to compare course planning for groups of faculty members who differ in some characteristic of interest, for example, discipline, status, longevity, pedagogical preparation, or teaching situation. In this paper, we use the framework to guide an analysis of whether part-time and full-time faculty members are influenced by different factors as they plan their courses.

Such an analysis is, of course, based on the assumption that part-time faculty members are an important group to study. The importance of part-timers is supported by both recent increases in their number and speculative concern for how their employment may affect students' education. About $30 \%$ of all faculty are part-timers and no decline is anticipated (Gappa, 1984). Several recent commentators have expressed alarm about this substantial proportion of part-time faculty and its long-range consequences for quality in higher education (e.g., Bowen and Schuster, 1986; NIE, 1984). Because the introductory educational experiences of many students depend on course plans constructed by these part-time faculty members, it is useful to compare their course planning assumptions with those of full-time faculty. Evidence about key differences between the two groups of faculty teaching in the same discipline and in similar colleges can help policy makers judge whether current concern is well-founded. 


\section{RELATED LITERATURE}

The literature about part-time faculty, mostly descriptive or anecdotal, focuses on such issues as demographic characteristics, institutional policies and employment practices, and the impact on institutions of using part-timers (Biles and Tuckman, 1986; Gappa, 1984; Leslie, Kellams, and Gunne, 1982; Miller, 1987; Mortimer, Bagshaw, and Masland, 1985; Parsons, 1980; Wallace, 1984). Despite concerns about quality control, the educational role of part-time faculty has received very little research attention. This research deficit has been highlighted in recent literature reviews (Gappa, 1984; Leslie, Kellams, and Gunne, 1982; Miller, 1987).

The few empirical studies comparing instructional practices of full-timers and part-timers have been conducted in two-year colleges and have used small, unrepresentative samples, typically drawn from single campuses. An exception is the study reported by Friedlander (1980). Using data from three nationwide studies of community college faculty, he reported differences between full- and part-timers on the following variables: teaching experience, textbook selection, use of instructional media in class, use of instructional support services, availability to students, and involvement in professional activities. The percentage differences, reported in the aggregate rather than by teaching field, indicated that the full-time faculty were better prepared and more involved with instruction. Friedlander concluded that, overall, instructional quality in two-year colleges is adversely affected by a high proportion of part-time to full-time faculty.

A recent study of part-time instructors in a four-year Canadian institution focused primarily on faculty status, but some of the findings on educational matters can be interpreted as contradictory to Friedlander's conclusion (Warme and Lundy, 1988). In the Canadian college, part-timers were heavily involved in teaching core courses and researchers concluded that the "professors" full-time or part-time status has little salience for students' experience of the teaching situation" (p. 211). For example, in survey responses only $10 \%$ of the students indicated the competence of part-time faculty was less than that of full-time faculty, $13 \%$ responded that part-timers' competence was higher, and 44 percent said it was "about the same."

At this time, the evidence from research literature does not support meaningful comparisons of the educational practices of full-time and part-time faculty. Studies have been based in different types of colleges and have used distinctly different variables and data sources, thus producing equivocal conclusions. If investigators continue to aggregate disciplines that depend on part-timers differentially and that use different underlying educational assumptions, future results will remain ambiguous. Thus far, researchers have 
largely ignored the process of course planning that reveals the foundational assumptions faculty members bring to the teaching task.

\section{PURPOSE AND RATIONALE}

In this paper we explore whether full-time and part-time faculty members report different influences as they plan introductory courses. As mentioned earlier, the broader survey study for which the data were collected was guided by the contextual filters model of course planning that includes three broad domains: (1) "content," including faculty background, disciplinary views, and educational views; (2) "context," focusing on situational influences; and (3) course decisions. Thus, in the content domain, faculty respondents reported on their background and preparation, views of their disciplines, and views on the purpose of education and judged how these influenced their course planning. In the context domain, they gave their perceptions of how strongly each of a variety of situational influences affected their planning. In the course decision domain, they rated the extent to which they pursue typical steps in planning, and prefer certain ways of arranging content. Finally, they rated sources for assistance in planning. Information about the college at which each faculty member taught was gathered from standard data sources and entered into the data base.

The following four questions were addressed in this analysis:

1. Do full-time and part-time faculty differ in personal and professional background, institutions of employment, and courses taught?

2. Do different influences affect full-time and part-time faculty as they plan introductory courses?

3. Do full-time and part-time faculty report different course-planning activities and decisions?

4. Do full-time and part-time faculty view different sources of assistance helpful for course planning and teaching?

\section{METHOD AND SAMPLE}

The data for this study were taken from a national survey designed to explore how faculty members from different fields and colleges plan introductory college courses (Stark, Lowther, Bentley, Ryan, Genthon, Martens, and Wren, 1989). A random set of 267 institutions was selected, encompassing $10 \%$ of each Carnegie classification except research universities and specialized institutions. Of the selected institutions, 97 four-year and two-year colleges agreed to participate; those declining cited concern about requesting faculty 
time. The participating institutions were similar to the randomly drawn invited sample when compared on Carnegie type $\left(\chi^{2}=10.8, d f=5, p=.06\right)$ and on eight independently determined institutional characteristics: enrollment; control (public, independent); selectivity (six levels); location (urban, rural); geographic location (nine regions); accrediting region (six regions); commuter orientation (proportion of resident students); and state level coordination (strong or weak board). Participating colleges were, however, significantly more often of religious origin than nonparticipants.

All part-time and full-time faculty in the participating colleges who were teaching introductory courses in English composition, literature, history, sociology, psychology, educational psychology, biology, mathematics, fine arts, romance language, nursing, and business were asked to complete the survey. Term-by-term variation in the population of faculty members teaching introductory courses precluded a precise determination of the response rate; we estimate that between $57 \%$ and $62 \%$ of the invited faculty responded. The response rate differed slightly by discipline; estimates range from $51 \%$ in business and English composition to $85 \%$ in nursing. Because of the difficulty some colleges reported in reaching part-timers, we suspect that they were slightly underrepresented as compared to full-time faculty members.

Of the 2,311 usable surveys, $23.4 \%$ were completed by faculty who identified themselves as part-time. Table 1 shows the distribution of the full-time and part-time faculty responses used in this analysis by both academic field and Carnegie institutional type. Fields were included in the analysis if at least $20 \%$ of faculty responding were part-timers. Based on this criterion, the four fields not included in the analysis were literature (11.5\% part-time); biology (10.7\%), educational psychology (14.6\%), and nursing $(9.0 \%)$.

Comparing institutional settings, the highest proportion of part-time teachers responding was employed in two-year colleges; $39.0 \%$ of the two-year college instructors reporting on their introductory courses in all eight fields were part-timers. Other types of colleges employed up to 26\% part-timers. In English composition, most colleges used part-timers extensively; the percent of composition teachers who were part-time faculty members at the various types of colleges ranged from $28 \%$ to $50 \%$.

\section{ANALYSIS}

From previous research we know that influences on course planning are highly discipline-specific (Stark, Lowther, Ryan, Bomotti, Genthon, Haven, and Martens, 1988; Stark, Lowther, Ryan, and Genthon, 1988). Thus, instructional and curricular comparisons that lump diverse fields together may reach faulty conclusions. To avoid this problem, we compared full-time and 


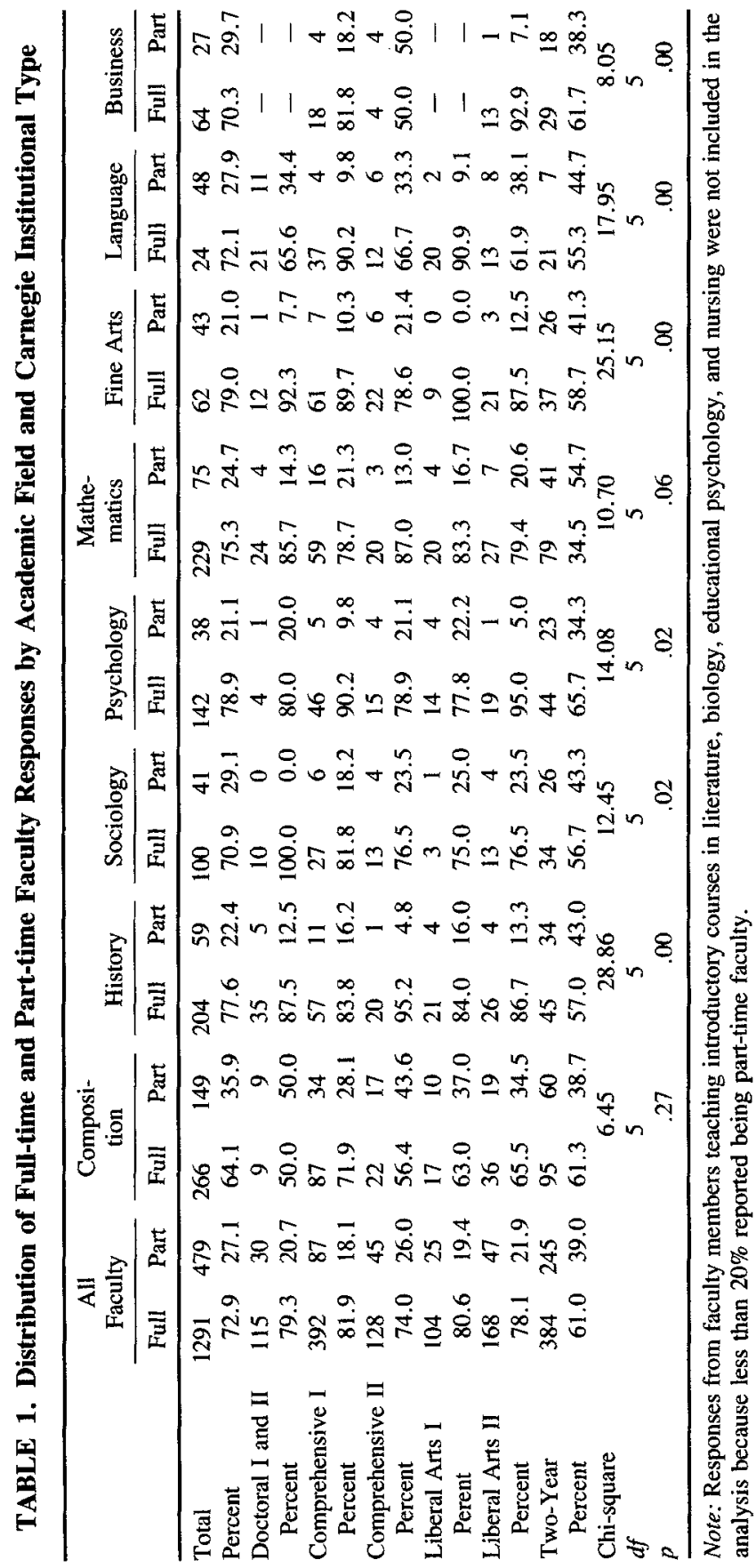


part-time faculty within discipline groups, according to the course they were teaching and reporting on in the survey. We focus our attention on comparing responses of full-time and part-time faculty members within each academic field. However, to illustrate how the aggregated data may produce misleading interpretations, we selectively report parallel analyses of the total sample of full-time and part-time faculty members.

The analysis began with univariate comparisons of part-time and full-time faculty on selected survey responses and standardized factor scores based on the contextual filters model. The derivation of the factors is reported elsewhere (Stark, Lowther, Bentley, and Martens, 1990) and their assigned domains and names (see Table 2) convey their content. Subsequently, hierarchical, set-wise discriminant analysis was chosen as the primary method of multivariate comparison, using part-time and full-time faculty as the groups within each field to be compared. This technique allowed determination of whether the two groups can be statistically separated based on consideration of demographic or course-planning variables grouped in conceptually similar sets. It allowed us to add variable sets sequentially to ascertain whether or not discrimination was improved by addition of a particular set. Finally, the discriminant analysis technique permits an attempt to classify individual respondents as belonging to the part-time or full-time groups based on the discriminating variables. The sets of variables included in the discriminant analyses are listed in Table 2 and are described briefly below. Separate analyses were conducted for each of the eight academic fields.

In Table 2, variables sets 1 and 2 are personal/professional and institutional variables, respectively, associated with each faculty respondent. Note that Carnegie type was not included in the discriminant analysis as an institutional characteristic because univariate analyses showed very few differences by type for any course planning variables once disciplines were considered separately. The more specific characteristics of institutional selectivity, urban location, and enrollment were judged to represent college variations with greater potential for affecting differences between full-time and part-time faculty members.

To compare influences on course planning for part-time and full-time faculty in the "content" domain of the contextual filters model, the following sets of factor scores were used: (set 3 ) faculty members views of their academic field ( 3 factors); (set 4) content and background influences on course planning (6 factors). An additional set of variables in this same domain (set 5) was comprised of faculty responses on five-point Likert-type scales to a series of statements representing varied beliefs about the purpose of education.

To explore potential differences concerning situational influences on course planning (the "context" domain of the model), a set of eight factors was used. These factors are shown as set 6 in Table 2.

To explore differences in the "course decisions" domain, we used faculty 


\title{
TABLE 2. Variable Sets on Which Full-time and Part-time Faculty Responses Were Compared
}

\author{
Set 1. Personal and Professional Characteristics \\ Age \\ Sex (dummy) \\ Possession of doctorate (dummy) \\ Years as graduate assistant \\ Years of high school teaching \\ Years employed in college teaching \\ Set 2. Institutional Characteristics \\ Selectivity \\ Urban location (dummy) \\ Enrollment
}

Domain: "Content" (Faculty Background, Discipline, Educational Beliefs)

Set 3. Views of Academic Field (Derived Standardized Factor Scores)

1. Organized body of knowledge, concepts, and operations

2. Group of individuals exploring related interests and values

3. Set of skills to be mastered and applied

Set 4. Content and Background Factors Influencing Course Planning (Derived Standardized Factor Scores)

1. Importance of concept learning

2. Importance of individual student development

3. Importance of vocational development

4. Influence of scholarly preparation

5. Influence of educational beliefs

6. Influence of religious, political, and social beliefs

Set 5. Beliefs About the Purpose of Education. (Likert Scales 1-5)

1. Teaching students to think effectively

2. Helping students to clarify values and make commitments

3. Pursuing systematic instructional objectives regardless of topic to be taught

4. Helping students learn to make the world a better place to live

5. Teaching students the great ideas of humankind

6. Helping students gain personal enrichment

7. Preparing students diretly for jobs

Domain: "Context" (Situational Factors)

Set 6. Contextual Influences on Course Planning (Derived Standardized Factor Scores)

1. Student characteristics

2. Student goals

3. Pragmatic issues

4. Influences external to the college

5. Program and college goals

6. Advice available on campus

7. Literature on teaching and learning

8. Facilities, resources, opportunities, assistance

Domain: Course Decisions

Set 7. Typical Steps in Course Planning (Likert Scales 1-5)

1. Select content

2. Think about student characteristics

3. Set objectives based on external goals

4. Set objectives based on own background 
TABLE 2. Continued

5. Select activities, materials, resources

6. Select objectives based on how students learn

7. Consider previous student evaluations

8. Consider previous examination results

Set 8. Preferred Basis for Sequencing Course Content (Likert Scales 1-5)

1. Concepts of the field

2. How students learn

3. The way knowledge is organized in the world

4. The way knowledge is created

5. Helping students use knowledge

6. Helping students clarify values

7. Student vocational needs

Set 9. Helpfulness of Fifteen Sources of Advice About Course Planning and Teaching (Likert Scales $1-5$ and N/A)

ratings indicating "how typical" certain steps are that faculty might take during course planning (Table 2, set 7). Similarly, also using responses to 5-point Likert-type scales, we included a set of items that probed preferences for varied ways of arranging course content (Table 2, set 8).

Finally, we reported, but did not include in the discriminant analysis, faculty ratings of the potential helpfulness of fifteen possible sources of assistance in course planning and teaching. Although it was not possible to develop a more parsimonious set of factors from these diverse items regarding sources of assistance, differences among full-time and part-time faculty members could have particular implications for improving teaching support systems.

\section{RESULTS}

The results will be presented according to the four research questions posed.

\section{Characteristics of Full-Time and Part-Time Faculty}

Do full-time and part-time faculty differ in personal and professional background, institution of employment, and courses taught?

The answer to this research question was a definitive yes. As shown in Table 3 , in almost every field, part-time faculty differed from full-time faculty in several personal and professional characteristics. Part-time faculty were significantly more likely to be female, nontenured, and without regular academic rank. They less frequently possessed the doctorate, more often had taught in high school, and had much less experience teaching in college and teaching the particular course on which they reported. In a few disciplines they were younger than their full-time colleagues. As would be expected, however, 


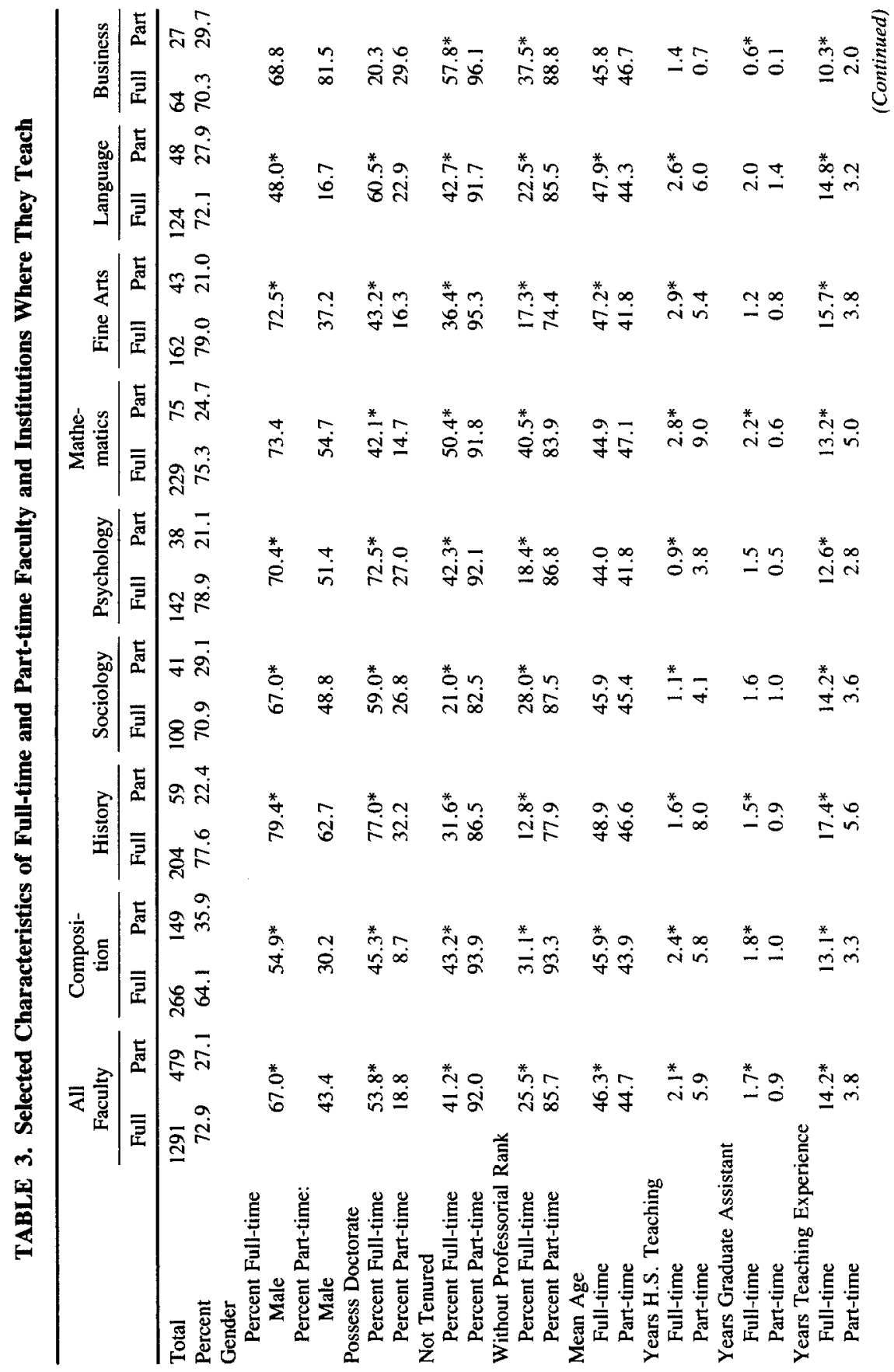




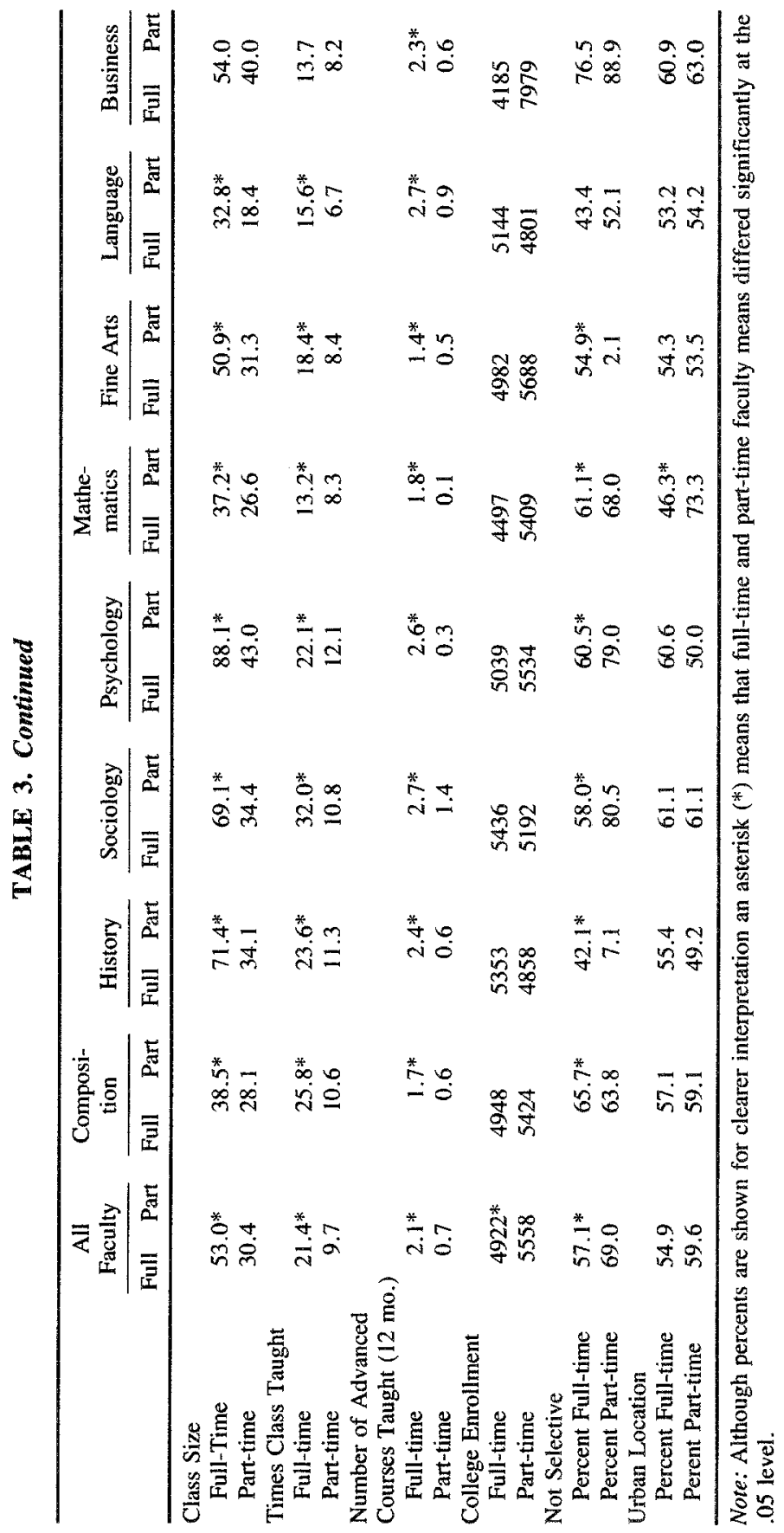


wide variations occurred among fields. For example, $81.5 \%$ of the part-time business faculty members were men, but only $16.7 \%$ of the part-time romance language teachers were men.

As numbers of respondents in the subgroups allowed, we pursued these comparisons further by comparing the characteristics of full-time and part-time faculty within each discipline for three different types of institutions: doctoral or comprehensive colleges, liberal arts colleges, and two-year colleges. These detailed comparisons are not shown in tables but, in general, part-time faculty teaching in five disciplines differed from full-time faculty as described above for all types of colleges. The exceptions were for the fields of sociology, romance language, and business. In these fields, the demographic characteristics of full-time and part-time faculty were very similar at all types of colleges.

With respect to their places and conditions of employment, part-timers were more likely to teach in nonselective institutions (including, but not limited to, community colleges). The institutions in which part-timers were employed were similar in enrollment to those employing the full-timers, however, and about as likely to be located in urban areas. Part-timers taught fewer advanced courses in their fields, yet their classes were significantly smaller than those taught by full-timers.

Summary results of the discriminant analyses performed separately for each academic field that show the canonical correlations and the extent to which Wilks' lambda was reduced from 1.0 after entry of each set of variables are given in Table 4. These results are based on responses of 1088 full-time and 362 part-time faculty members after listwise deletion of respondents with missing data.

Because academic rank and tenure status of part-timers so obviously differentiated them from full-timers, these variables were not entered into the discriminant analysis lest they mask the contribution of other variables. Even so, the remaining personal variables (see Table 2 , set 1) significantly distinguished full-time and part-time faculty members. Six items of personal information produced separations between the full-time and part-time faculty members, resulting in canonical correlations $\left(R_{c}\right)$ ranging from .31 to .52 for the various disciplines (see Table 4, step 1). Thus, the personal variables explained from $9.6 \%$ to $27 \%$ of the variance between the two groups $\left(R_{c}{ }^{2}\right)$, depending on the disciplines. Wilks' lambda was substantially reduced-from 1.00 to .73 in romance languages - and strongly separated the two groups in these fields. ${ }^{1}$ Wilks' lambda was reduced least in business (.91), indicating fewer differences between full-time and part-time faculty in this field. These results were supported by postanalysis classification results. For example, in history, it was possible to classify part-time and full-time faculty modestly well $(79.6 \%$ correct 


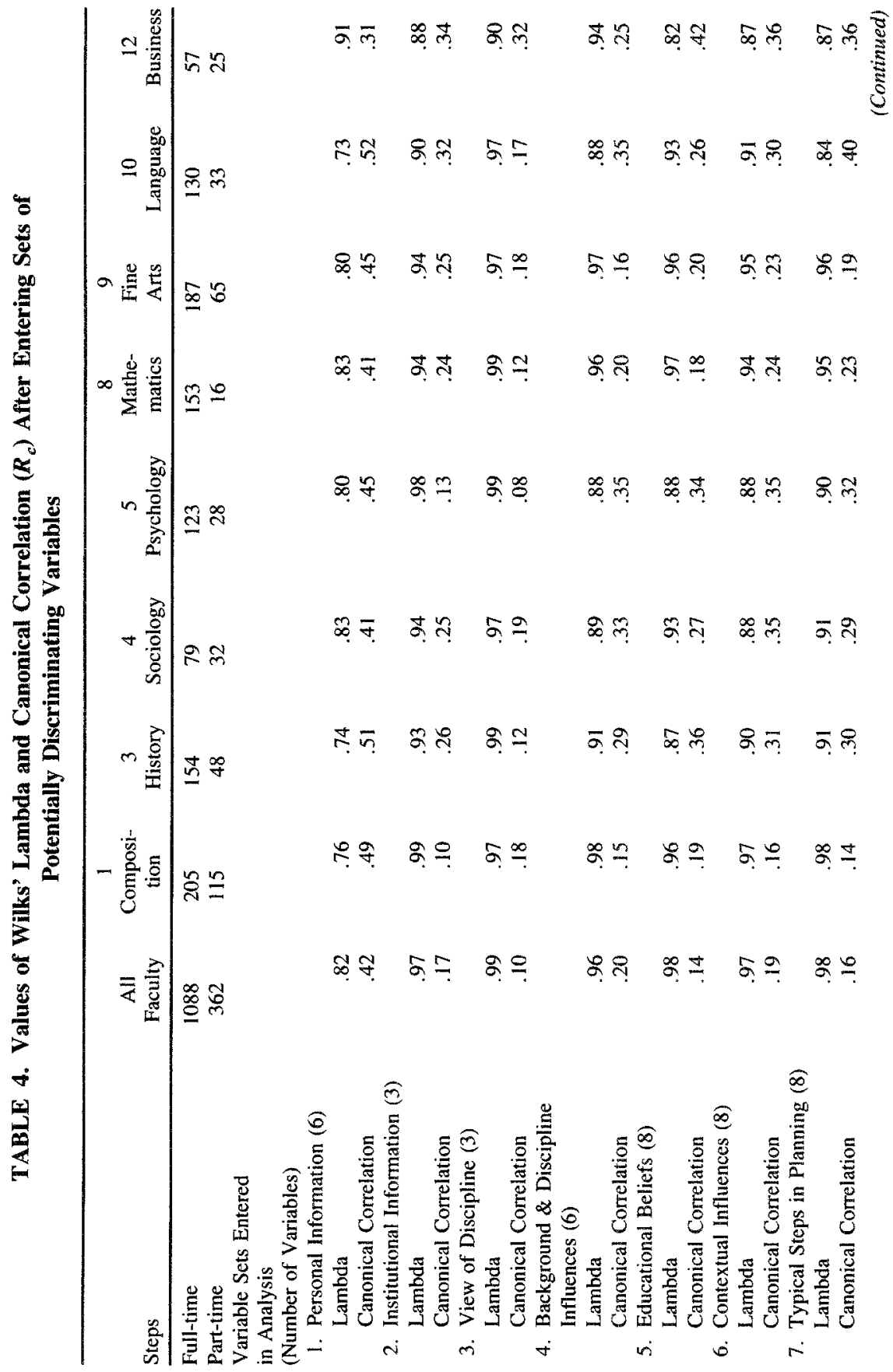




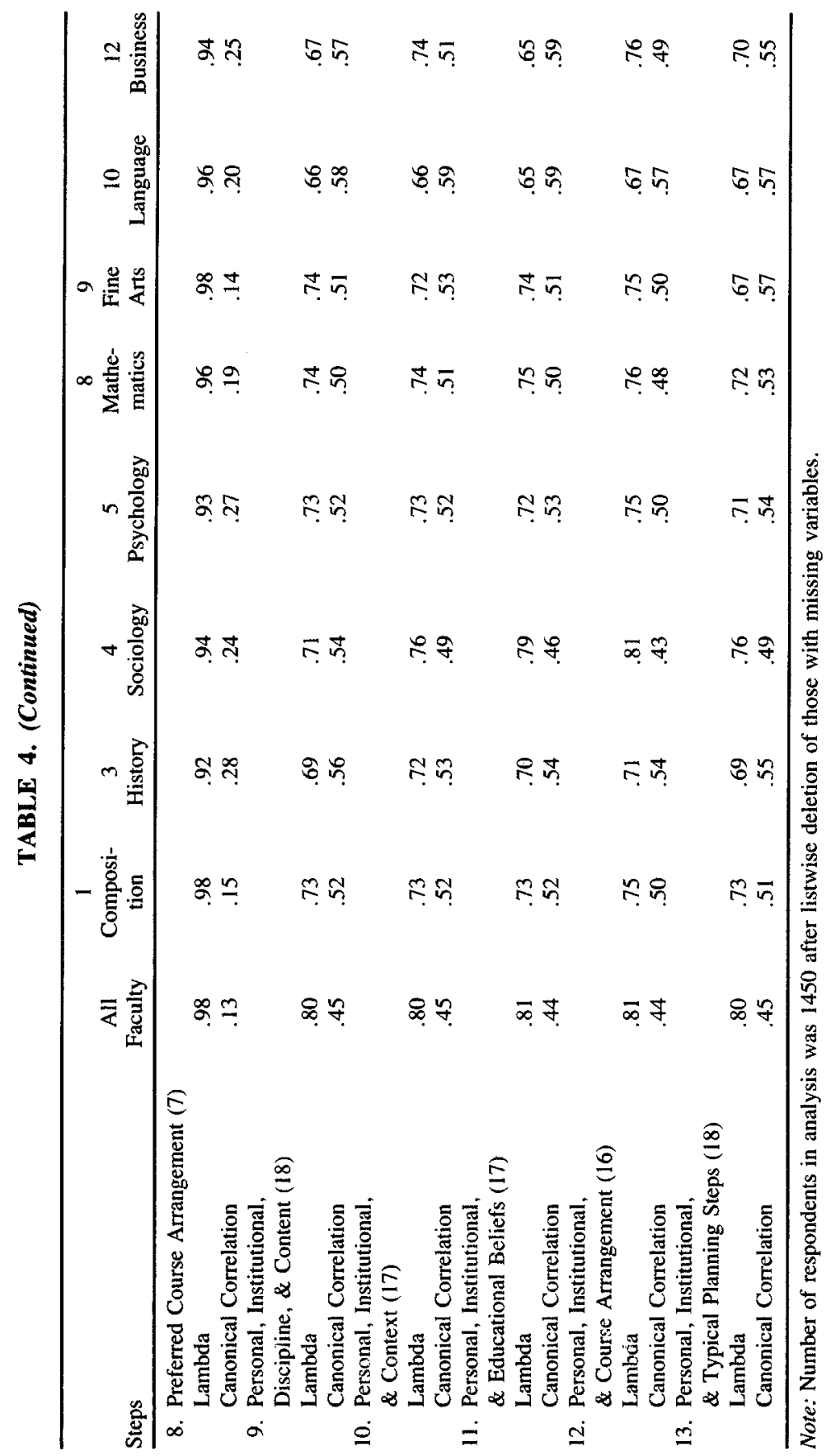


classifications); for business, the $59.6 \%$ correct classification was only slightly better than would be expected by chance.

In contrast to personal and professional characteristics, very little discrimination or correct classification of full-time and part-time faculty was obtained based on three variables characterizing the institution of employment: selectivity, urban location, enrollment (Table 2, set 2). Wilks' lambda was reduced only to .99 for English composition, consistent with the univariate analysis finding of few differences among part-time and full-time composition faculty in quite different institutions. The greatest separation based on institutional characteristics was in business (lambda $=.88$ ).

\section{Influences on Course Planning}

Do different influences affect full-time and part-time faculty as they plan introductory courses?

Full-time and part-time faculty reported different course planning influences when the aggregated sample was considered. When fields were considered separately, however, univariate comparisons ( $t$-tests) between the part-time and full-time groups for the variables in each set of influences on course planning showed only a few statistically significant differences $(p<.05)$ between the two groups. These few differences rather consistently occurred on variables in the "content" domain of the model involving beliefs about educational purpose.

Specifically, part-time faculty seemed to differ from full-timers in attributing more importance to student vocational development, job preparation, and value development. These same differences were reflected in the course decisions domain; regardless of college type, part-time faculty members more frequently reported trying to arrange course content in ways that facilitate student utilization of knowledge outside the classroom or help students develop values.

Among contextual influences, part-timers reported greater influence from goals external to the college, such as employers, accreditors, or professional associations. These differences seem logical, since in many fields part-time faculty would be expected to bring a more vocational emphasis to their teaching and perhaps be more attuned to goals of external agencies than those of the college. We accept such logical results cautiously, however, not only because the significant differences were few but because in nearly every significant case the mean scores of part-time faculty on variables and factors were higher than those of full-time faculty. An alternative explanation is that part-time faculty members may simply respond more strongly on the continua provided in surveys.

When variable sets $3,4,5$, and 6 were entered in discriminant analysis 
separately, each analysis produced a low canonical correlation, very modest reductions of Wilks' lambda (ranging from .82 to .99), and no correct classifications of full-time and part-time faculty members much better than chance predictions $(<60 \%)$. These variables, representing influences in the content and context domains of the model, differentiated full-time from part-time faculty only weakly. The discrimination was not quite as strong as that based solely on personal/professional differences (see Table 4, steps 3-6).

\section{Course Planning Activities}

Do full-time and part-time faculty report different course-planning decisions and activities?

As with course planning influences, there were only scattered significant differences between full-time and part-time faculty in the course planning decisions or steps they report (Table 2, sets 7 and 8 ). Entering these variables as sets into discriminant analysis did not enable us to distinguish between full-time and part-time faculty or to correctly classify them (see Table 4 , steps 7 and 8 ). This lack of differences between the two types of faculty was found, as well, when the faculty members teaching in a given discipline were examined by type of institution.

\section{Combined Analyses}

Finally, the sets of personal variables and institutional variables (sets 1 and 2) were entered into discriminant analysis first, then followed by each of the sets of variables within the three domains: content (sets 3, 4, and 5), context (set 6), and course decisions (sets 7 and 8). Because of the limited numbers of cases available for analysis within the separate disciplines, only one set of variables at a time from each domain was added to sets 1 and 2. Thus, a maximum of 18 variables was used in any analysis. The results are shown in Table 4, steps 9-13. When added, none of the sets of variables related to course planning provided discrimination substantially greater than that achieved by considering personal variables alone.

\section{Sources of Assistance}

Do full-time and part-time faculty view different sources of assistance as helpful for course planning and teaching?

In Table 5 we display selected mean ratings (on a 5-point scale from not helpful to extremely helpful) given by full-time and part-time faculty as they considered various sources of assistance in planning their courses. Pairs of 


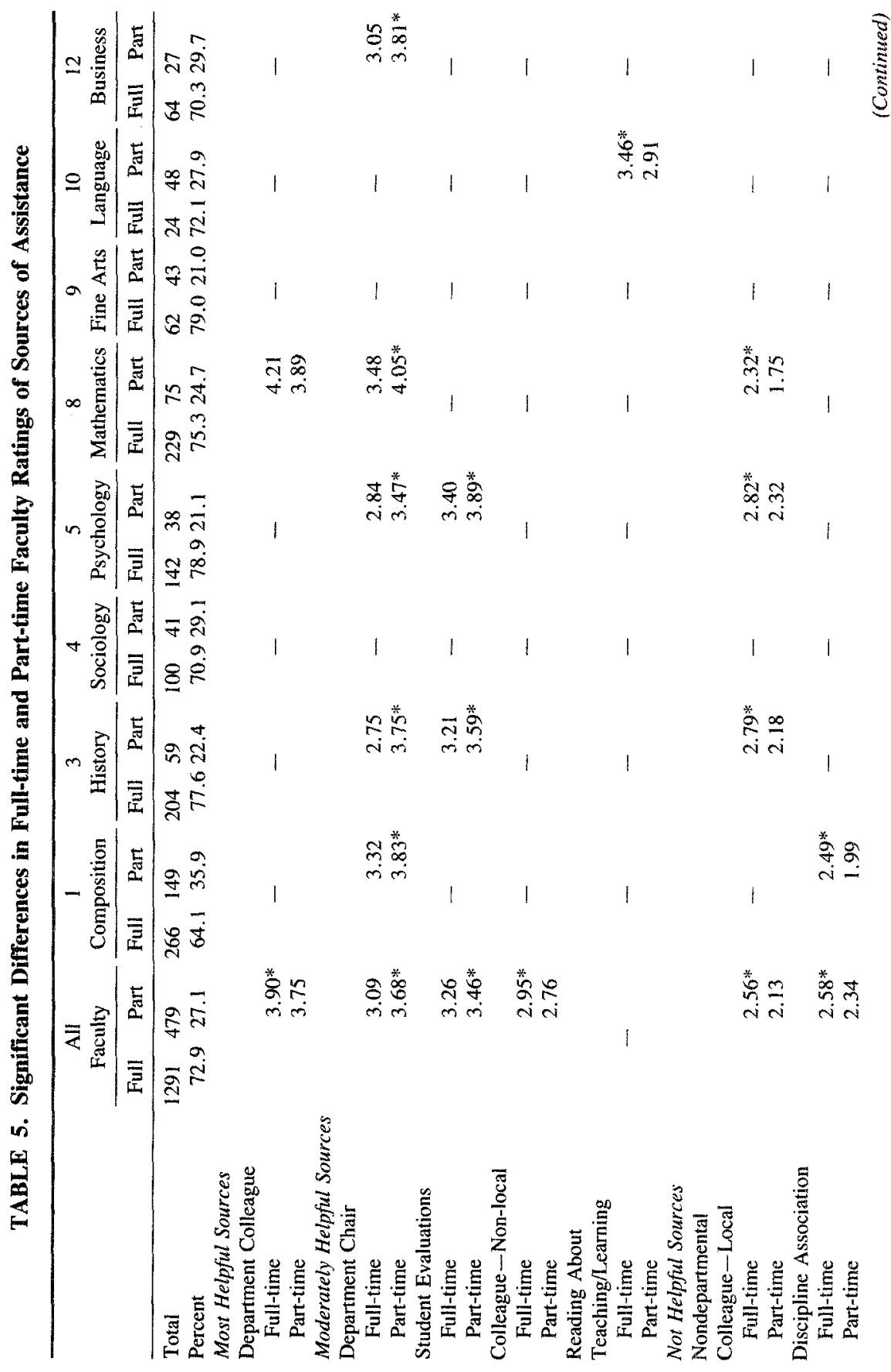




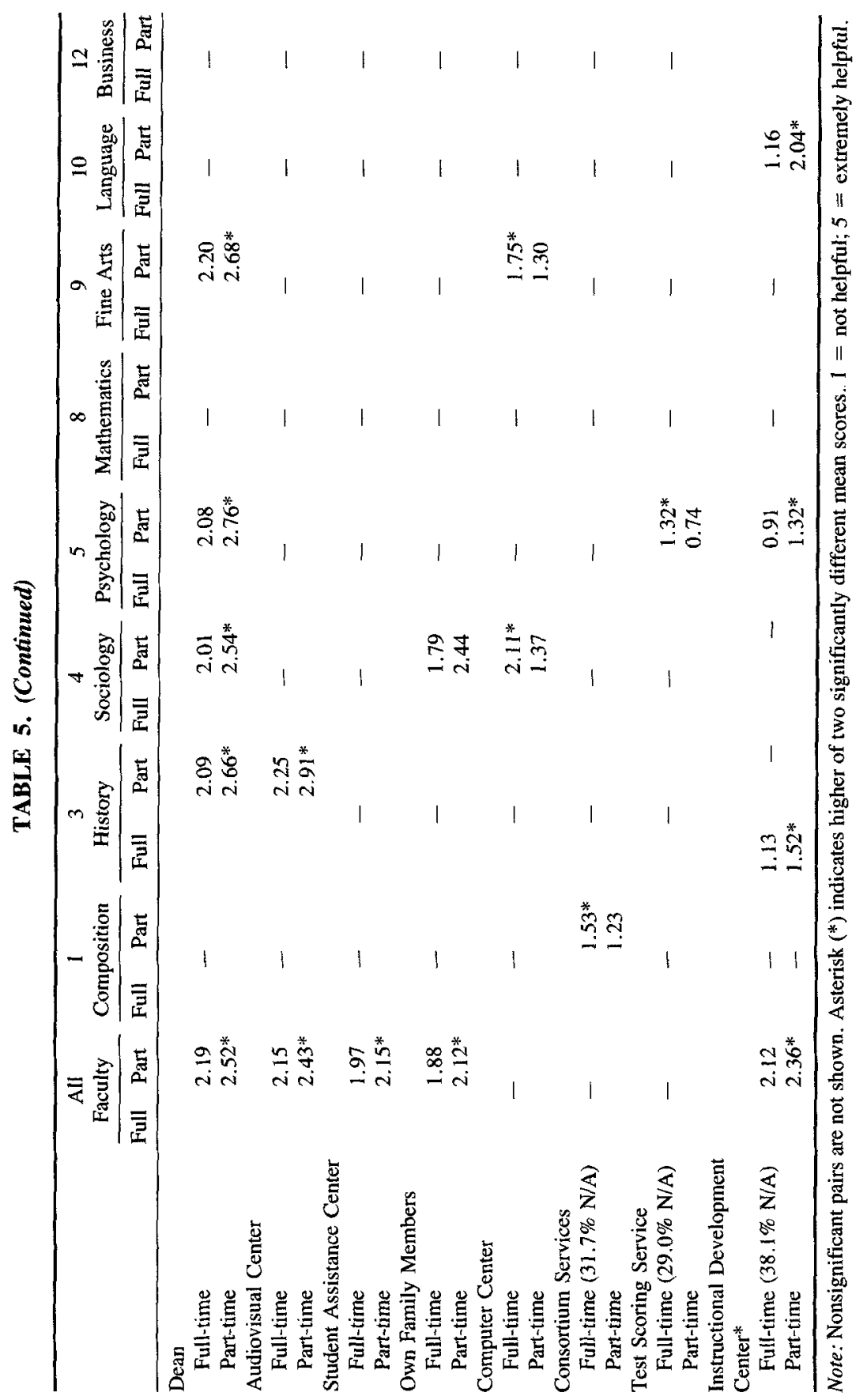


means shown are significantly different $(p<.05)$ when compared with $t$-tests; means were not recorded if not significantly different. Based on the responses of all faculty respondents, we have grouped the sources of assistance in order of decreasing helpfulness in roughly three sets (very helpful, moderately helpful, not very helpful). ${ }^{2}$

Compared to other variable sets there was a somewhat larger number of statistically significant univariate comparisons between full-time and part-time faculty with respect to the sources of assistance they see as helpful. Among sources that most faculty find moderately helpful, part-time faculty in several fields were more likely to find the department (or division) chair to be helpful than were full-time faculty. Although less helpful in general, the part-timers were also more likely to find the dean helpful. In contrast, full-time faculty appeared to turn more frequently to local colleagues outside their department, perhaps because they have more opportunities to interact with such faculty.

\section{DISCUSSION}

This study sought to determine if part-time faculty members could be distinguished from full-time faculty members teaching in the same disciplines by the views they held toward planning introductory courses or the planning activities they reported. The choice of variables to examine was guided by the three domains of influence on course planning included in the contextual filters model of course planning. To control for differences among disciplines in faculty planning assumptions, separate analyses were conducted for eight academic fields. Inclusion was limited to fields in which at least $20 \%$ of the faculty members teaching similar introductory courses were part-timers. The sample of faculty teaching these courses was drawn from 97 colleges. Examination of the possible effect of varied teaching contexts was based on college selectivity, enrollment, and urban location. Faculty self-reported their personal and professional characteristics.

The most important finding of the study was that part-time and full-time faculty did not differ on substantive content-related influences that enter into course planning. Views of the teaching field, estimates of the influence of their own background on planning, and espoused beliefs about education for part-timers closely resembled those of full-time faculty teaching in the same field. Univariate analyses of the data suggested that part-time faculty members may view education as more vocationally directed and value-oriented than do full-timers. These differences, however, did not distinguish among the two types of faculty members in a multivariate analysis.

Similarly, no differences were found between full-time and part-time faculty concerning the strength of influences on planning within the instructional 
environment or in the course planning steps and content arrangements faculty preferred. Possibly, the enhanced vocational emphasis of part-timers was reflected in reports of stronger influence from goals external to the college and in a preference for arranging course content to foster use of material by students in practical ways.

Instructors' views of where to find helpful assistance in course planning differed modestly for full-time and part-time faculty in field-specific instances. Part-timers may turn to administrative superiors such as deans and department chairs for help more frequently than do full-timers.

The primary difference identified in this study (aside from status issues of rank and tenure) was that the full-time faculty have stronger credentials in their disciplines and have taught in college longer, whereas part-timers have weaker disciplinary credentials and less experience in college teaching but often have taught for many years in high school settings. No differences were found that indicated these background differences cause faculty members to think differently about course planning.

Course planning is a complex, problem-solving venture, in which faculty members make curricular and instructional decisions involving a wide range of factors. In doing so, instructors must make creative use of their background and scholarly preparation. As a foundational element in the instructional process, course planning is one important indicator of faculty quality. Had we found differences in the responses of full- and part-timers, we could justifiably raise questions about the quality of course planning. The fact that we did not find differences should lead administrators and policy makers to be cautious in assuming that instructional practices of part-time faculty are automatically inferior to those of full-time faculty in the same field.

But since our study involved only one aspect of instructional practice, neither should administrators believe that all is necessarily well. Given that part-time faculty have demonstrably less extensive preparation in their discipline, there is reason for disciplinary experts in each field to compare in more detail the depth and breadth of course plans prepared by full-time and part-time faculty. Part-timers, in contrast, have more extensive high school teaching experience and, perhaps, more pedagogical training. Thus, a complete and fair comparison should also include teaching experts who can judge the process as well as the plan. In the set of courses we examined, taught at the introductory level for each field, the pedagogical expertise gained from high school teaching may have some merit. On the other hand, recent recommendations that the most prestigious professors in each discipline teach beginning undergraduates (NIE, 1984) are also worthy of attention. Perhaps the essential issue is one of achieving balance between disciplinary and pedagogical expertise, based on adequate information about how these affect learning.

We found few prior studies with which to compare our own. Some of our 
findings regarding the professional characteristics of part-timers resemble those of Friedlander (1980), who also found that part-timers had less college teaching experience. Friedlander found less use of media and other instructional support services by part-timers, whereas we found small discipline-specific differences between the views of the two groups about whether these services were helpful. Lack of use could imply an access or orientation problem as well as a lack of motivation or involvement for part-time faculty members. Of course, since Friedlander did not separate the faculty by academic field, he may have uncovered discipline variations in instructional practice that characterize full-time faculty as well.

This study was exploratory and, as far as we can determine, one of the first national investigations of faculty thought processes about college teaching. As Clark and Peterson (1986) state, the study of teacher cognitive activities is a new "paradigmatic approach to research on teaching" (p. 257), and contrasts with the process-product paradigm where the focus is on teacher classroom actions or student outcomes. The process-product approach has been used in both $\mathrm{K}-12$ and college education to study faculty teaching behavior with various degrees of success. One reason may be that to understand faculty teaching one must understand faculty thought processes that strongly influence action.

Our study of course planning is a first step in understanding how faculty decisions are influenced by their beliefs about subject matter, students, educational purpose, and their teaching situation. Since course planning is an important landmark on the route to educational quality, the finding that part-timers and full-timers do not differ much in their thinking about it helps to rule out one major source of the presumed differences. Yet, our research is still too limited to conclude that part-timers are either more or less effective as planners than full-timers.

Additional comparisons, always analyzed by discipline, are needed to explore how part-time and full-time faculty members' thinking about their teaching directs their activities when in the classroom, affects their relations with students, and, of course, influences student learning. Ours was a first step in exploring territory about which many assumptions have been made without much evidence. It should encourage others to investigate other aspects of instructional practice to solve the full-time-part-time dilemma.

Acknowledgment. This article is derived from a report of the National Center for Research to Improve Postsecondary Teaching and Learning (NCRIPTAL) under OERI Grant No. G008690010. The studies described are from the NCRIPTAL Program on Curriculum Influences and Impacts. The opinions expressed are those of the authors. The authors appreciate the assistance of other members of the research team, Michael P. Ryan and Gretchen G. Martens, with various aspects of this report. 


\section{NOTES}

1. The greater the discrimination between two groups as successive explanatory discriminant functions are derived, the more closely will the Wilks' lambda statistic approach zero. Thus, a Wilks' lambda close to the maximum value of 1.00 indicates that any differences between the two groups cannot be well explained by the variables tested as potential discriminators. A value of 1.00 would indicate that the two groups are identical with respect to the variables under consideration.

2. Note, however, that for the last three potential sources of assistance in Table 5 (consortium services, test scoring services, and instructional development centers) over one-fourth of the respondents indicated the service did not exist on their campus. We substituted small numbers (close to zero) for missing responses to indicate "lack of helpfulness" of these nonexistent services. While not affecting the comparison, these reported means are somewhat lower than would be the case if the calculation were based only on those campuses where services exist.

\section{REFERENCES}

Biles, G. F., and Tuckman, H. P. (1986). Part-Time Faculty Personnel Management Policies. New York: Macmillan.

Bowen, H. R., and Schuster, J. H. (1986). The American Professoriate: A National Resource Imperiled. New York: Oxford University Press.

Clark, C. M., and Peterson, P. L. (1986). Teachers' thought processes. In M. C. Wittrock (ed.), Handbook of Research on Teaching, 3rd ed., pp. 874-905. New York: Macmillan.

Friedlander, J. (1980). Instructional practices of part-time faculty. In M. H. Parsons (ed.), Using Part-Time Faculty Effectively: New Directions for Community Colleges, No. 30, pp. 27-36. San Francisco: Jossey-Bass.

Gappa, J. M. (1984). Part-Time Faculty: Higher Education at a Crossroads. ASHE-ERIC Higher Education Report No. 3. Washington, DC: Association for the Study of Higher Education.

Leslie, D. W., Kellams, S. E., and Gunne, G. M. (1982). Part-Time Faculty in American Higher Education. New York: Praeger.

Lowther, M. A., and Stark, J. S. (April 1990). Course planning patterns of college teachers. Paper read at the American Educational Research Association. Boston.

Miller, R. J. (1987). The impact of part-time faculty in the learning environment. Journal of Continuing Higher Education 35(2): 5-10.

Mortimer, K. P., Bagshaw, M., and Masland, A. T. (1985). Flexibility in Academic Staffing: Effective Policies and Practices. ASHE-ERIC Higher Education Report No. 1. Washington, DC: Association for the Study of Higher Education.

National Institute of Education. Study Group on the Conditions of American Higher Education (1984). Involvement in Learning: Realizing the Potential of American Higher Education. Washington, DC: U.S. Government Printing Office.

Parsons, M. E. (ed.) (1980). Using Part-Time Faculty Effectively. New Directions for Community Colleges. No. 30. San Francisco: Jossey-Bass.

Stark, J. S., and Lowther, M. A. (1986). Designing the Learning Plan: A Review of Research and Theory Related to College Curricula. Technical Report 86-C-001. Ann Arbor, MI: University of Michigan, National Center for Research to Improve Postsecondary Teaching and Learning. 
Stark, J. S., Lowther, M. A., Ryan, M. P., and Genthon, M. (1988). Faculty reflect on course planning. Research in Higher Education 29(3): 219-240.

Stark, J. S., Lowther, M. A., Ryan, M. P., Bomotti, S. S., Genthon, M., Haven, C. L., and Martens, G. (January 1988). Reflections on Course Planning: Faculty and Students Consider Influences and Goals. Ann Arbor, MI: National Center for Research to Improve Postsecondary Teaching and Learning, University of Michigan.

Stark, J. S., Lowther, M. A., Bentley, R. J., Ryan, M. P., Genthon, M. L., Martens, G. G., and Wren, P. (March 1989). Planning Introductory College Courses: Influences on Faculty-A Synopsis of Findings. Ann Arbor, MI: National Center for Research to Improve Postsecondary Teaching and Learning, University of Michigan.

Stark, J. S., Lowther, M. A., Bentley, R. J., and Martens, G. G. (1990). Disciplinary differences in course planning. Review of Higher Education 13(2): 141-165.

Wallace, M. E. (ed.) (1984). Part-Time Academic Employment in the Humanities. New York: Modern Languages Association.

Warme, B., and Lundy, K. (1988). Erosion of an ideal: The presence of part-time faculty. Studies in Higher Education 13(2): 201-213.

Received August 21, 1990 